Military Technical College Kobry El-Kobba

Cairo, Egypt

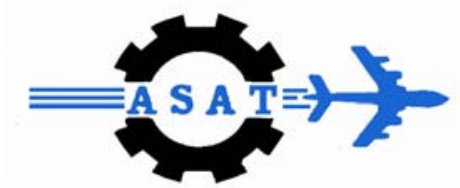

12-th International Conference

on

Aerospace Sciences \&

Aviation Technology

\title{
EFFECT OF AMMONIUM PERCHLORATE GRAIN SIZE ON COMBUSTION OF A SELECTED COMPOSITE SOLID PROPELLANT
}

\author{
$\operatorname{HEGAB}^{1 *}$, A. M. and BALABEL ${ }^{2 *}, A$.
}

\begin{abstract}
The heterogeneous propellants consisting of Ammonium Perchlorate (AP) particles imbedded in a Hydroxyl Terminated Polybutadience (HTPB) are widely used in solid rocket industries. In this study, the effect of AP particles diameter and the random distribution with the HTPB on the burning of such propellant is presented. A mathematical model which describes the unsteady burning of a heterogeneous propellant by simultaneously solving the combustion fields in the gas phase and the thermal field in the solid phase with appropriate jump condition across the gas/solid interface is developed. The gas-phase kinetics is represented by a two-step reaction mechanism for the primary premixed flame and the primary diffusion flame between the decomposition products of the HTPB and the oxidizer AP. The propagation of the unsteady non-planer regression surface is described, using the Essentially-NonOscillatory (ENO) scheme with the aid of the level set strategy. The results show that the large AP particle diameter has a marked effect on the combustion surface deformation and on the burning rate as well. Therefore, modeling of the condensed phase process is mostly conducted on AP. Moreover, the effect of various parameters on the surface propagation speed, flame structure, and the burning surface geometry is obtained.
\end{abstract}

\section{KEYWORDS}

Composite propellant, gas/solid phases, heterogeneous propellant, AP/HTPB, Level Set Method.

\section{NOMENCLATURE}
$A_{A P, B}$
reaction rate constant
$C_{p}$ specific heat
D diffusivity

\footnotetext{
$1^{*}$ Associate Professor, Dpt. of Mech. Power Engineering, Faculty of Engineering, Menoufia University, Shebin Elkom, Egypt.

${ }^{2 *}$ Lecturer, Dpt. of Mech. Power Engineering, Faculty of Engineering, Menoufia University, Shebin Elkom, Egypt.
} 


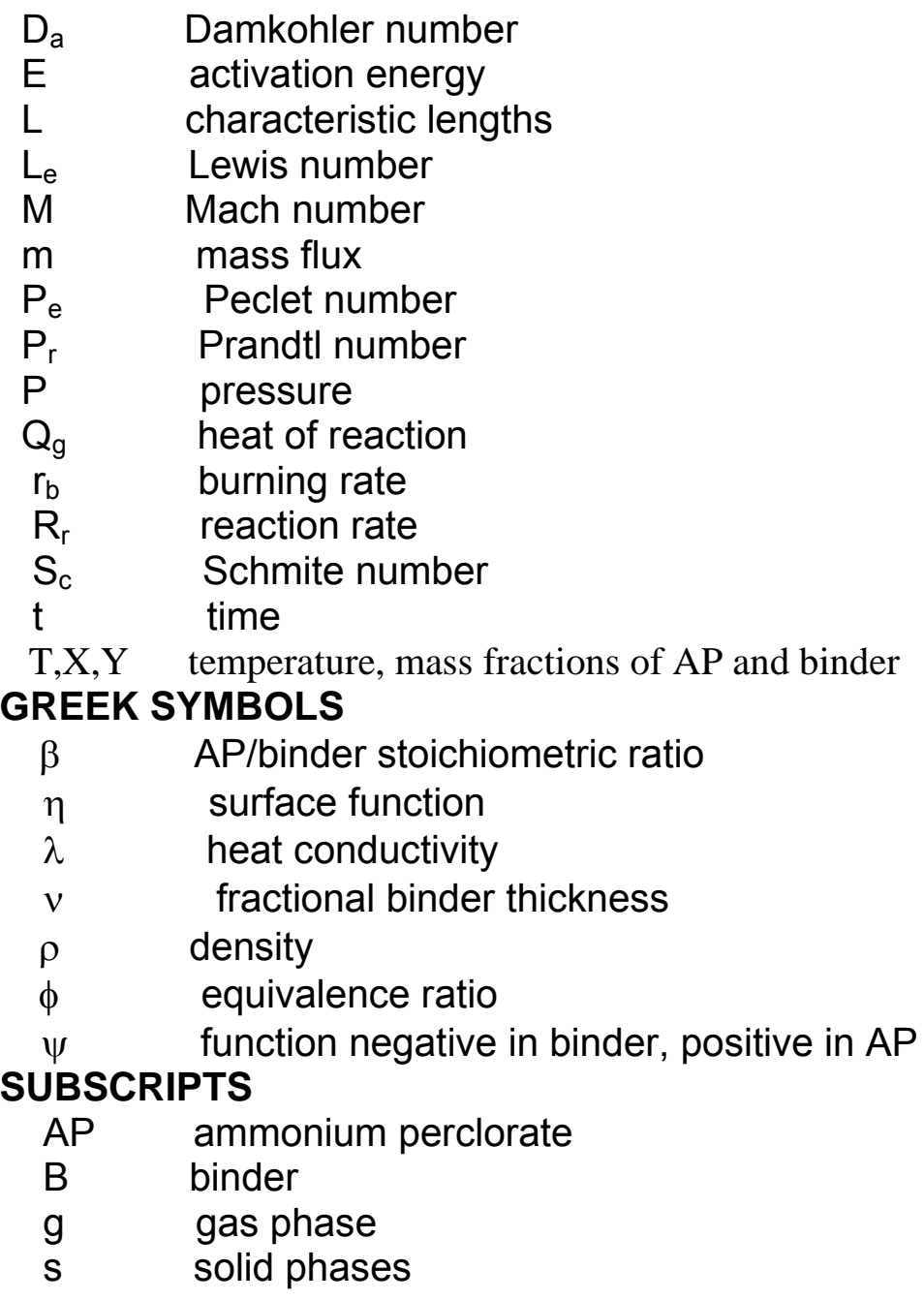

\section{INTRODUCTION}

The complex flame structure that is generated by burning of a heterogeneous solid rocket propellant is proposed by Beckstead, Derr, and Price (the BDP model [1]), as shown schematically in Fig.1. Three separate flames can be identified in the gas phase. 1. a primary flame between the decomposition products of the binder and the oxidizer, 2 . a premixed oxidizer flame, and 3. a final diffusion flame between the products of the other two flames. In spite of the BDP model is one-dimensional and necessarily omits or fails to properly account for important physics, but attempts to account for many of the significant feature of the combustion field. The influence of this work (published in 1970) still endures [2], and 1D models are still used [3]. Several improvements to BDP model of steady-state burning have been conducted. Lee et. al. [4] presented a modified picture for the flame structure for AP-Binder-AP sandwich as in Fig.2. This sketch show the principles of the combustion zone, in which the oxidizer-fuel flames consists of a leading-Edge Flame (LEF) that stands in the mixing region of the oxidizer and fuel vapors, and a diffusion flame that trails from the LEF up to a point where the fuel vapor is all consumed. The LEF is a region of very high heat release as compared to the rest 
of the diffusion flames and contributes most of the heat transfer back of the propellant surface. This edge occurs because the diffusion flame can not extend all the way to the surface, the temperature there being too low.

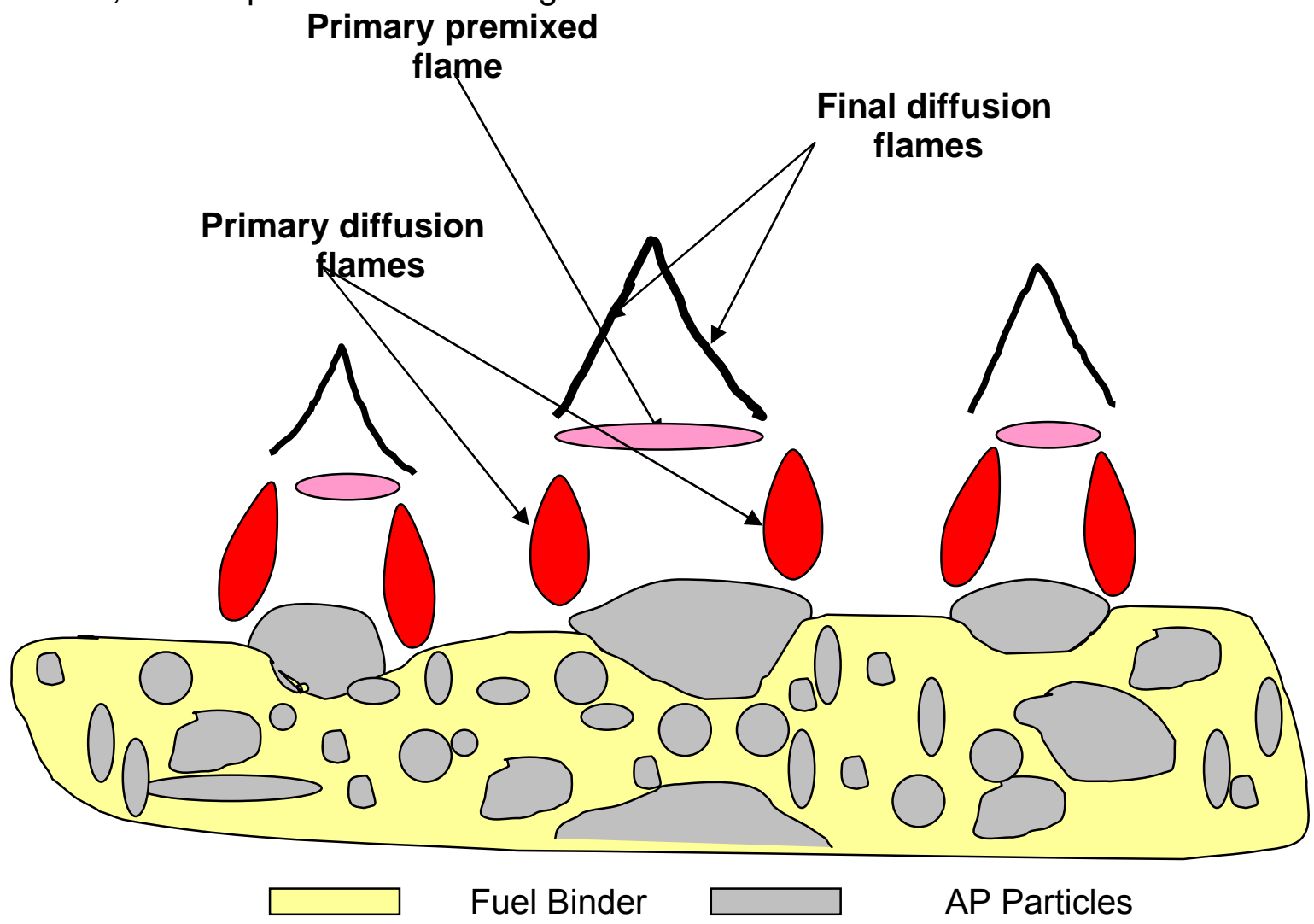

Figure 1: Flame Structure of AP/Binder Composed Propellant Proposed by Beckstead, Derr, and Price [1].

The theoretical studies for the combustion of heterogeneous solid rocket propellant have faced a lot of difficulties because of the chemical and physical complexity of the propellant and the microscopic scale of the combustion zone. Therefore, few experimental studies have been performed for the simplest model of the combustion of Ammonium Perchlorate sandwiches [4,5]. The propellant was made from sheets of APbinder-AP. The AP formed by dry pressing ultra pure AP powder. Four different binders were used. Observations for the combustion were made by high-speed photography and microscopic examination of quenched samples. In addition, Lee et.al. [4] illustrated the effect of inclusion of particulate AP in the binder on the combustion surface and the flame structure. The effect of three types of fuel binder and oxidizer particle diameter on the decomposition and combustion behavior of ammonium perchlorate is studies by AlHarthi and Williams, [ 6]. Few decades ago, several theoretical studies on the combustion field of the burning of the heterogeneous propellant have been conducted. These researches are divided into two main categories. The first one is concentrated on the gas phase modeling without consideration for the condensed phase process, for example $[7,8,9,10,11]$. The second one is studied the condensed phase reaction as the most important factor, for example [12,13]. 
Recently the complex coupling between the solid-phase and gas-phase process becomes the most factor as a natural step. In particularly, the complexity that arises from the consideration of the unsteady non-planar regression surface, as in[14,15,16].

In the present paper a complete numerical strategy account the following ingredients: the primary flame between the decomposition products of the binder and the oxidizer (AP), the primary diffusion flame from the oxidizer (AP), different properties (density, conductivity) of the AP and binder, temperature-dependent gas-phase transport properties, an unsteady non-planer regression surface. These ingredients are applied to the problem of Periodic 2D packing disks with different AP grain sizes distributed in a HTPB fuel-binder.

\section{The PHYSICAL MODELS}

In this section the essential component of constant density model is described. It has long been recognized that the burning rate of the rocket propellant is influenced by the propellant morphology, by the size and size distribution of the ammonium perchlorate (AP) particles. In spite of, the sandwich models that we have mentioned above used as a convenient platform on which to generate the numerical code for the complex flame structure, but much serious attempt to simulate propellant burning numerically must incorporate a packing algorithm. In another word, a strategy for defining and constructing a model of packing rocket propellant numerically was required at that time.

Fortunately, the packing algorithm is one that is of interest of several scientific fields and has been studied both experimentally and numerically.

McGeary, in 1961 [17] reported a brief description of some experiments on the packing of steel shot. Bimodal packing was investigated in which spheres of diameter 0.124 in. are packed with smaller spheres. The packing volume is defined as the volume of the particles plus the interstitial volume. The packing fraction $\rho$ (the fraction of the packing volume that is particles) is measured as a function of the volume fraction of fine particles (the volume of fine particles divided by the total volume of particles); the results are reproduced in Fig. 2. When the particle volume fraction is 0 or $100 \%$, the packing is monomodal and the packing fraction is approximately 0.625 .

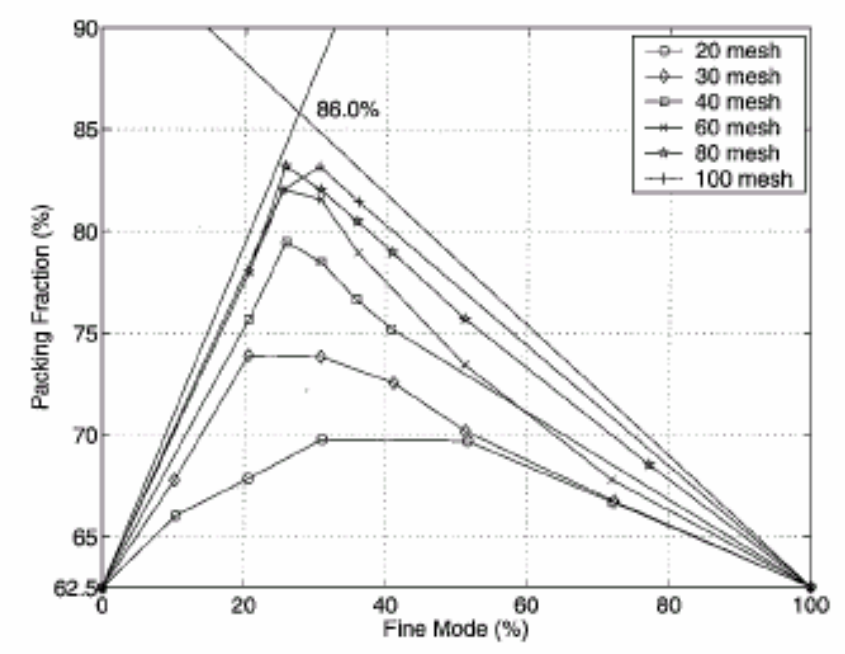

Fig. 2 McGeary's data for packing fraction [17]. 
Higher packing fractions are achieved for bimodal packs and the greater the disparity in sizes, the greater the packing fraction. In all cases, the maximum occurs at approximately $30 \%$ fine, $70 \%$ coarse. The largest packing fraction is 0.8594 .

A mathematical models for the $2 \mathrm{D}$ random packing strategies have developed by Kochevets, et.al. [18,19] , Knott, et.al. [20], and Buckmaster, et.al. [21,22] in order to numerically construct models of heterogeneous rocket propellants. Their packing algorithms are based on the integration of the random packing approach and the collision theory that has been described in a number of papers by Lubachevsky and his Colleagues in 1990,1991 [23] and by Zhang et.al. in 2001, [24]. These models deal with 2D combustion field supported by a disk pack propellant, in which full coupling between the gas phase, the condensed phase, and the retreating nonplanar propellant surface was accounted for.

Recently, in 2007, Hegab [25] describes a large number of periodic 2D disk pack models by assuming that the particles of the AP are 2D disks and distributing them in a random fashion and applied to monomodal, bimodal, and multimodal disc packs. The disk packs that used in the current study are a large grey AP (300 micron) distributed with smaller sizes of AP grains (50 micron each) (model I as shown in Fig. 3a ), three large grey AP (200 micron each) distributed with smaller sizes of AP grains (50 micron each) (model II as shown in Fig. 3b), and twenty two equal sizes grey AP grains (185 micron each) distributed with smaller sizes of AP grains (47 micron each) (model III as shown in Fig. 3c ).

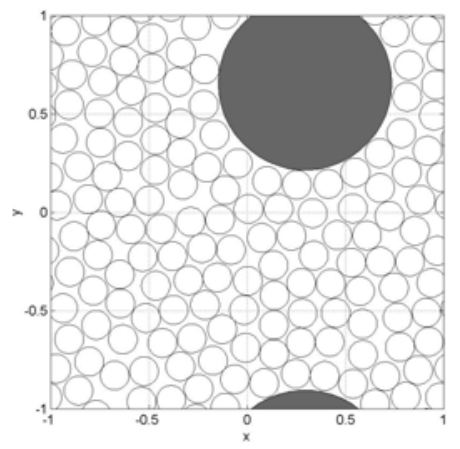

(a)

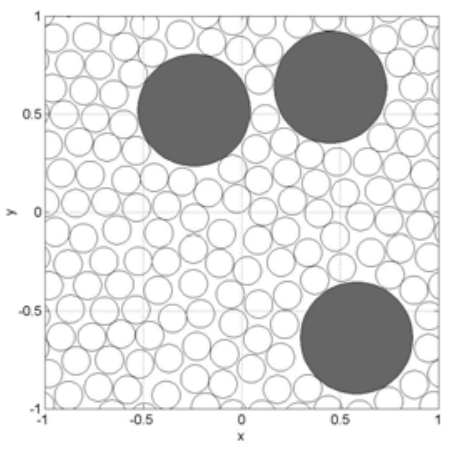

(b)

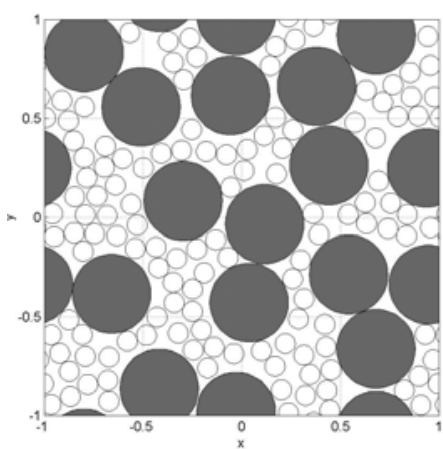

(c)

Fig. 3 : 2D bimodal disk packs. (a) Model (I) (b) Model (II), (c) Model(III)

These three models $(I, I I, I I)$ have the same packing fraction $(\rho)$ about 0.79 in order to play around the experimental packing density as mentioned above. The length scale is 500 microns.

\section{KINETICS, GAS AND SOLID PHASES, MOVING GAS/SOLID INTERFACE EQUATIONS}

\section{1) Two-Step Kinetic Equations}

The BDP model identifies three kinds of flames, but it has long been argued that the "primary diffusion flame," in which AP and binder gases react, is not important. The two survivors are the AP decomposition flame and the final diffusion flame in which the 
AP decomposition products react with binder gases; these two flames are part of the two-dimensional model discussed here.

The two-step kinetics that include the AP decomposition flame and the final diffusion flame is examined in order to achieve a good understanding of the unsteady burning of periodic 2D disk pack propellant with complete coupling between the solid and gas phases. Thus

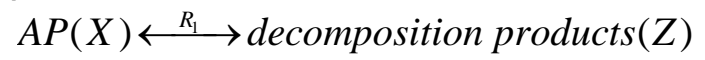

$\beta Z+\operatorname{Binder}(Y) \stackrel{R_{2}}{\longleftrightarrow}$ final products

(1)

$\mathrm{R}_{1}$ and $\mathrm{R}_{2}$ are assumed to have the forms

$$
\begin{aligned}
& \mathrm{R}_{1}=\mathrm{B}_{1} \mathrm{P} \mathrm{X} \exp \left(\frac{-\mathrm{E}_{1}}{\mathrm{R}_{\mathrm{u}} \mathrm{T}}\right) \\
& \mathrm{R}_{2}=\mathrm{B}_{2} \mathrm{P}^{2} \mathrm{ZY} \exp \left(\frac{-\mathrm{E}_{2}}{\mathrm{R}_{\mathrm{u}} \mathrm{T}}\right)
\end{aligned}
$$

Where B's are the exponential prefatory, E's are the activation energy in the gas phase, $P$ is the pressure, $R_{u}$ is the universal gas constant, and $(T, X, Y$ and $Z$ ) are the temperature, oxidizer, fuel and the decomposition products respectively.

\section{2) Gas Phase Equations}

The corresponding gas phase equations are;

$$
\rho_{g} \frac{\partial \phi}{\partial t}=\vec{\nabla} \cdot\left(\frac{\lambda_{g}}{c_{p}} \vec{\nabla} \phi\right)+\psi R
$$

where; $\phi=\left[\begin{array}{c}T \\ X \\ Y \\ Z\end{array}\right], \quad \psi=\left[\begin{array}{l}Q_{g 1} R_{1} / c_{p}+Q_{g 2} R_{2} / c_{p} \\ -R_{1} \\ -R_{2} \\ +R_{1}-\beta R_{2}\end{array}\right]$

The above equations represent the constant density model. The specific details of the constant density model for our problem are as follows: the density is set equal to constant (so that the equation of state, Charles law, is jettisoned); and a uniform velocity field $\mathrm{u}=0$ and $\mathrm{v}(\mathrm{y})=$ constant is adopted, which satisfies both the continuity and momentum equations. Lewis number is taken to be unity, then;

$$
\rho_{g} D_{g}=\lambda_{g} / c_{p}
$$

With the aid of the equation of state;

$$
P=\rho R T
$$

\section{3) Solid-Phase and Solid/Gas Interface Equations}

In the solid-phase, the following heat equation is used;

$$
\rho_{s} T_{t}=\frac{\lambda_{s}}{c_{p}} \nabla^{2} T
$$


Here, $\rho_{s}$ is the density of the solid, $T$ the temperature, and $\lambda_{s}$ is the solid thermal conductivity. The specific heat $c_{p}$ is assumed to be equal to that in the gas phase for simplicity. The possibility of differing densities and thermal properties in the solid phase is allowed and setted by;

$$
\rho_{s}=\left\{\begin{array}{ll}
\rho_{A P} & \lambda_{s}=\left\{\begin{array}{ll}
\lambda_{A P} & \psi \geq 0 \\
\rho_{B} & \psi<0
\end{array},\right.
\end{array},\right.
$$

The function $\psi(\mathrm{x}, \mathrm{y})$ is a level set function which demarks the regions of AP from binder (B) within the solid, so that a point $(x, y)$ lies in the AP if $\psi(x, y) \geq 0$, and in the binder if $\psi(\mathrm{x}, \mathrm{y})<0$. Suppose the solid/gas interface defined by $\eta(\mathrm{x}(\mathrm{t}), \mathrm{y}(\mathrm{t}), \mathrm{t})=0$. Then;

$$
\eta_{t}+\eta_{x} \frac{d x}{d t}+\eta_{y} \frac{d y}{d t}=0
$$

and the final equation that control the moving of the gas/solid interface as in Fig. 2 is derived by Hegab, et.al. $[14,15]$ and may be written as follows;

$$
\eta_{t}-r_{b}|\vec{\nabla} \eta|=0
$$

where $r_{b}$ is defined as the speed of the front which moves in the directions of the solid. In general $r_{b}$ is a function of $x$ and $t$ and is given by the following simple pyrolysis law;

$$
r_{b}=\left\{\begin{array}{lc}
r_{A P}=A_{A P}\left(P / P_{0}\right)^{n_{A P}} \exp \left\{-E_{A P} / R_{u} T_{A P, S}\right\} & \psi \geq 0 \\
r_{B}=A_{B}\left(P / P_{0}\right)^{n_{B}} \exp \left\{-E_{B} / R_{u} T_{B, s}\right\} & \psi<0
\end{array}\right.
$$

Note that pressure dependence has been added to the pyrolysis law for generality. In the study, the propellant surface is not flat and its shape changes with time. Therefore, the following mapping function is used;

$$
\eta=y-f(x, t)
$$

and the the front of equation (10) reduces to the simple Hamilton-Jacobi equation;

$$
f_{t}+r_{b}(x, t) \sqrt{1+f_{x}^{2}}=0,
$$

Further information about the non-planar moving of the gas/solid interfaces using the Level Set strategy is mentioned in details in $[14,15]$.

\subsection{Boundary \& Jump Conditions}

The appropriate jump conditions across the gas /solid interface are;

$$
\begin{aligned}
& {\left[\rho\left(\vec{v} \cdot \vec{n}+r_{b}\right)\right]=0 ;} \\
& {[T]=0 ;} \\
& {[\lambda \vec{n} . \nabla T]=-Q_{s} m ;} \\
& \quad m\left[Y_{i}\right]=\left[\rho D \vec{n} . \nabla Y_{i}\right], \quad i=1,2,3,
\end{aligned}
$$

where $[\phi]=\phi_{\mathrm{g}}-\phi_{\mathrm{s}}$ denotes the jump in the quantity $\phi$ across the interface, $\mathrm{m}$ is the mass flux. $\vec{n}$ is the unit normal pointing in the direction of the gas; $\vec{n}=\nabla \eta /|\nabla \eta|$, figure (3). $\mathrm{Q}_{\mathrm{s}}$ is the solid phase heat release term defined by

$$
Q_{s}= \begin{cases}Q_{A P} & \psi \geq 0 \\ Q_{b} & \psi \leq 0\end{cases}
$$


For an exothermic surface reaction, $Q_{s}>0$, and for an endothermic reaction, $Q_{s}<0$. Typically the AP is considered an exothermic reaction, while the binder an endothermic one.

The recent studies by Hegab, et.al. $[14,15]$ proved that the length and time scales for the front and the solid are the same order of magnitudes. On the other side, the ratio of the gas to solid or the ratio of the gas to front are of the order of $10^{-3}$. Thus for the present purpose, the quasi-steady approximation for the gas phase is employed. Note that disturbances with time scales of order $10^{-3} \mathrm{~s}$ would effect the solid phase, but not the gas phase; changes on time scales of order $10^{-5} \mathrm{~s}$ are needed to generate an unsteady gas phase and changes of this nature have been discussed in [11].

\section{Nondimensionalization}

The following reference values is taken to nondimensionalize the equations ;

$$
\begin{gathered}
T^{*}=T / T_{\text {rep }} X^{*}=X / X_{s}, Y^{*}=Y / Y_{s}, P^{*}=P / P_{o}, \stackrel{*}{\rho^{*}}=\rho \rho_{o},\left(u^{*}, v^{*}\right)=(u, v) / V_{g}, \quad f^{*}=f / L, r_{b}^{*}=r_{b} / r_{b, r e f}, \\
\left(x^{*}, \eta^{*}\right)=(x, \eta) / L, t^{*}=t / t_{s}, \quad t_{s}=L / r_{b, r e f}, \quad t_{g}=L / V_{g}, \quad \varepsilon=t_{g} / t_{s}<<1 \\
V_{g}=\rho_{A P} r_{b, r e f} / \rho_{g}, T_{\text {ref }}=2700 \mathrm{~K}, Q_{\text {ref }}=\mathrm{c}_{\mathrm{p}}{ }^{*} 2700 \mathrm{cal} / \mathrm{g}
\end{gathered}
$$

Pressure $p_{o}(\mathrm{~atm})$, surface speed $r_{b, r e f}(\mathrm{~cm} / \mathrm{s})$, and mass flux $m_{\text {ref }}=\rho_{A P} r_{b, r e f}$. Length $L$ (half of the computational domain, which is the sum of the binder and the AP thickness). Time $\mathrm{t}=\mathrm{L} / \mathrm{r}_{\mathrm{b} \text {,ref. }}$. Then the following non-dimensional parameters are defined: Peclet numbers $P_{e g}=\rho_{g} V_{g} L c_{p} / \lambda_{g}$,ref, and $P_{e c}=\rho_{A P} r_{b, r e f} L c_{p} / \lambda_{A P}$, Activation energy $\theta=E /\left(R_{\mathrm{u}} \mathrm{T}_{\text {ref }}\right)$

$$
\begin{gathered}
\hat{Q}_{s}= \begin{cases}Q_{s, A P} /\left(c_{p} T_{\text {ref }}\right) & \psi \geq 0 \\
Q_{s, B} /\left(c_{p} T_{\text {ref }}\right) & \psi<0,\end{cases} \\
\lambda_{\text {ratio }}= \begin{cases}1 & \psi \geq 0 \\
\lambda_{B} / \lambda_{A P} & \psi<0,\end{cases} \\
\rho_{\text {ratio }}= \begin{cases}1 & \psi \geq 0 \\
\rho_{B} / \rho_{A P} & \psi<0 .\end{cases}
\end{gathered}
$$

In non-dimensional form the equations and boundary/connections form conditions are: $\eta\rceil 0$

$$
\begin{aligned}
& \varepsilon T_{t}+u T_{x}+\bar{v} T_{\eta}=\left(1 / P_{e_{g}}\right) \vec{\nabla} \cdot(\tilde{\lambda} \vec{\nabla} T)+Q_{g} R \\
& \varepsilon X_{t}+u X_{x}+\bar{v} X_{\eta}=\left(1 / P_{e_{g}}\right) \vec{\nabla} \cdot(\tilde{\lambda} \vec{\nabla} X)-R \\
& \varepsilon Y_{t}+u Y_{x}+\bar{v} Y_{\eta}=\left(1 / P_{e_{g}}\right) \vec{\nabla} \cdot(\tilde{\lambda} \vec{\nabla} Y)-R / \beta
\end{aligned}
$$

but temperature-dependent transport is accounted for, viz; $\lambda_{g}=\lambda_{\text {g,ref }} * \tilde{\lambda}\left(T, T_{\text {ref }}\right)$ where $\lambda_{\mathrm{g} \text {,ref }}$ is a reference heat conduction coefficient. The value of $\lambda$ at the reference

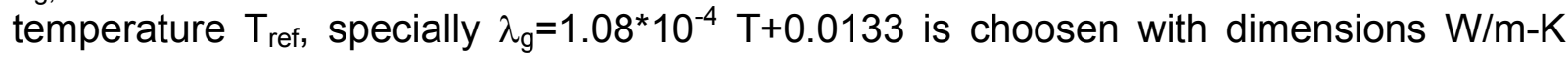
when $\mathrm{T}$ is assigned in degrees Kelvin, so that

$$
\tilde{\lambda}\left(T, T_{\text {ref }}\right)=\frac{1.08 * 10^{-4} T_{\text {ref }} T+0.0133}{1.08 * 10^{-4} T_{\text {ref }}+0.0133}
$$




$$
\begin{aligned}
& \mathrm{u}=0, \bar{v}=-\rho_{\text {ratio }} f_{t}, \\
& \mathrm{R}_{1}=\mathrm{D}_{\mathrm{a} 1} \mathrm{P} \mathrm{X} \exp \left(\frac{-\theta_{\mathrm{g} 1}}{\mathrm{~T}}\right) \\
& \mathrm{R}_{2}=\mathrm{D}_{\mathrm{a} 2} \mathrm{P}^{2} \mathrm{ZY} \exp \left(\frac{-\theta_{\mathrm{g} 2}}{\mathrm{~T}}\right)
\end{aligned}
$$

$\underline{\eta<0}$ (Solid Phase)

$$
\rho_{\text {ratio }}\left(T_{t}-f_{t} T_{\eta}\right)=\left(\lambda_{\text {ratio }} / P_{e c}\right) \Delta T
$$

\section{$\underline{\eta}=0$ (Moving Interface)}

$$
\begin{aligned}
& f_{t}+r_{b} \sqrt{1+f_{x}^{2}}=0 \text {, } \\
& T\left(x, 0^{+}, t\right)=T\left(x, 0^{-}, t\right) \\
& \left.\Lambda\left(\frac{-f_{x} T_{x}+\left(1+f_{x}^{2}\right) T_{\eta}}{\sqrt{\left(1+f_{x}^{2}\right)}}\right)\right|_{0^{+}}-\left.\hat{\lambda} \lambda_{\text {ratio }}\left(\frac{-f_{x} T_{x}+\left(1+f_{x}^{2}\right) T_{\eta}}{\sqrt{\left(1+f_{x}^{2}\right)}}\right)\right|_{0^{-}}=-\hat{Q}_{s} m P_{e_{g}} \\
& \left.\left(m X-\frac{\Lambda}{P_{e_{g}}}\left\{\frac{-f_{x} X_{x}+\left(1+f_{x}^{2}\right) X_{\eta}}{\sqrt{\left(1+f_{x}^{2}\right)}}\right\}\right)\right|_{0^{+}}=\left\{\begin{array}{cc}
m & \psi \geq 0 \\
0 & \psi<0
\end{array}\right. \\
& \left(m Y-\left.\frac{\Lambda}{P_{e_{g}}}\left\{\frac{-f_{x} Y_{x}+\left(1+f_{x}^{2}\right) Y_{\eta}}{\sqrt{\left(1+f_{x}^{2}\right)}}\right\}\right|_{0^{+}}= \begin{cases}0 & \psi \geq 0 \\
m & \psi<0\end{cases} \right. \\
& \underline{\eta \rightarrow \infty} \quad \mathrm{T}=\mathrm{T}_{\mathrm{o}} \\
& \underline{\eta \rightarrow+\infty} \quad \frac{\partial}{\partial \eta}(\phi)=0 \\
& |x|=1 \quad \text { Periodic boundary conditions }
\end{aligned}
$$

\section{NUMERICAL SOLUTION TO HAMILTON-JACOBI EQUATION}

The surface equation (13) is solved in order to follow the non-planar regression surface by the first order temporal scheme [26,27];

$$
f_{i}^{n+1}=f_{i}^{n}-\Delta t \phi\left(\frac{f_{i}^{n}-f_{i-1}^{n}}{\Delta x}, \frac{f_{i+1}^{n}-f_{i}^{n}}{\Delta x}\right)
$$

where $\phi$ is a numerical flux function. Here, $i$ denotes the discrete grid location $x_{i}, n$ the previous time level, and $n+1$ the new time level. Although there are many choices, the second-order Lax-Freidricks monotonic flux function is used;

$$
\phi_{L F}\left(u_{1}, u_{2}\right)=\frac{1}{2}\left(\frac{r_{b, i}+r_{b, i-1}}{2} \sqrt{1+u_{1}^{2}}+\frac{r_{b, i+1}+r_{b, i}}{2} \sqrt{1+u_{2}^{2}}\right)
$$

and $r_{b, i}$ is the local burn rate determined from the pyrolysis law. The CFL condition $\Delta \mathrm{t} \leq \mathrm{CFL} \Delta \mathrm{x}$ is satisfied for stability. Typically one would set $\mathrm{CFL}=\left(\max \left\{\mathrm{r}_{\mathrm{b}}\right\}\right)^{-1}$; however the value of $1 / 4$ seems satisfactory.

Beside the non-flat regression surface mapping as in (11), another transformation is applied for the cluster grid points in regions adjacent to the wall, where most of the flow parameters changes rapidly. The solution of the final mapped equations is advanced in 
the solid phase using physical time $(\mathrm{t})$. Simultaneously the solution in the gas phase using pseudo-time $(\tau)$ to the local steady state at the first physical time step (t) is advanced. The boundary/jump conditions are continually updated as in Eqs. (26) to (34). Then the Hamilton-Jacobi Eqn. (13) is advanced at the physical time by a third order ENO and a fifth-order WENO (weighted essentially non-oscillatory) solver $[28,29]$. All numerical calculations were performed on a $140 \times 70$ grid, uniform in the x-direction and stretched in the $y$-direction. The code in the gas phase is stopped between each two physical times when the relative difference between solutions at two different pseudo-time values is less than some prescribed tolerance, taken here to be $10^{-6}$. Convergence tests where carried out and it was determined that any further refinement resulted in less than $1 \%$ relative error.

\section{RESULTS AND DISCUSIONS}

The understanding of the complex combustion structure of the 2D disk pack of AP/HTPB propellant, as a simple model to the heterogeneous solid rocket propellant, is studied in details for three different bimodal packing models to show the effect of the AP grain sizes and distribution with the fuel binder on the combustion process, the burning rate, and the flame structure as well. The gas phase of these three models is the constant density model where the density is set equal to constant (so that the equation of state, Charles law, is jettisoned); and a uniform velocity field $u=0$ and $v(y)=$ constant is adopted, which satisfies both the continuity and momentum equations. Initially, the solution starts for the three models from a flat surface $f(x, t=0)=0$. Then the solution is advanced simultaneously in the solid/gas phases, with moving interface with appropriate jump conditions. Moreover, in these models, it has been taken $\mu=\Lambda\left(T, T_{\text {ref }}\right)$ which is one of the more realistic choices rather $\mu=$ constant.

Table 1: Thermophysical properties of the gas, AP, and Binder are fitted to the experimental data. The values of $A_{A P}$ and $A_{B}$ have been Chosen so that the pyrolysis law yields $r_{b, r e f}=0.25 \mathrm{~cm} / \mathrm{s}$ at $860 \mathrm{~K}$. [4]

\begin{tabular}{|c|c|c|c|}
\hline Parameters & Values & Parameters & Values \\
\hline 1. Gas Phase & & $\mathrm{Q}_{\mathrm{AP}}$ & $+100.86 \mathrm{kcal} / \mathrm{kg}$ \\
\hline$\rho_{\mathrm{g}}$ & $\mathrm{kg} / \mathrm{m}^{3}$ & $E_{A P}$ & $\mathrm{kcal} / \mathrm{mole}$ \\
\hline$\lambda_{g}$ & $0.209 \mathrm{~W} / \mathrm{m}-\mathrm{K}$ & $A_{A P}$ & $9.82 \times 10^{4} \mathrm{~cm} / \mathrm{sec}$ \\
\hline$C_{p}$ & $0.3 \mathrm{kcal} / \mathrm{kg}-\mathrm{K}$ & $\rho_{\mathrm{B}}$ & $920 \mathrm{~kg} / \mathrm{m}^{3}$ \\
\hline$Q_{g 1}$ & $675 \mathrm{kcal} / \mathrm{kg}$ & $\lambda_{\mathrm{B}}$ & $0.184 \mathrm{~W} / \mathrm{m}-\mathrm{K}$ \\
\hline $\mathrm{Q}_{\mathrm{g} 2}$ & $3127 \mathrm{kcal} / \mathrm{kg}$ & $\mathrm{C}_{\mathrm{B}}$ & $0.3 \mathrm{kcal} / \mathrm{kg}-\mathrm{K}$ \\
\hline$E_{g}$ & $31.2 \mathrm{kcal} / \mathrm{mole}$ & $Q_{B}$ & $-47.8 \mathrm{kcal} / \mathrm{kg}$ \\
\hline $\mathrm{R}_{\mathrm{u}}$ & $1.985 \mathrm{kcal} / \mathrm{kmole}-\mathrm{K}$ & $E_{B}$ & $\mathrm{kcal} / \mathrm{mole}$ \\
\hline 2. Solid Phase & & $A_{B}$ & $4.96 \times 10^{3} \mathrm{~cm} / \mathrm{sec}$ \\
\hline$E_{A P}$ & $22 \mathrm{kcal} / \mathrm{mole}$ & $\mathrm{T}_{0}$ & $300 \mathrm{~K}$ \\
\hline$E_{B}$ & $15 \mathrm{kcal} / \mathrm{mole}$ & $T_{\text {ref }, g}=Q_{g} / c_{p}$ & $2700 \mathrm{~K}$ \\
\hline$\rho_{A P}$ & $1950 \mathrm{~kg} / \mathrm{m}^{3}$ & $\mathrm{P}_{0}$ & $1 \mathrm{~atm}$ \\
\hline$\lambda_{\mathrm{AP}}$ & $0.628 \mathrm{~W} / \mathrm{m}-\mathrm{K}$ & $\mathrm{m}$ & $18 \mathrm{~kg} / \mathrm{m}^{2}-\mathrm{s}$ \\
\hline $\mathrm{C}_{\mathrm{AP}}$ & $0.3 \mathrm{kcal} / \mathrm{kg}-\mathrm{K}$ & $T_{\text {ref, }, A P, B}$ & $860 \mathrm{~K}$ \\
\hline
\end{tabular}


The first set of the results are for the reaction rates at different times as in Fig. $4 a$ and $b$ for the bimodal disk pack defined in models (I). (II), and (III), where a large grey AP (300 micron) distributed with smaller sizes of AP grains (50 micron each) (model I), three large grey AP (200 micron each) distributed with smaller sizes of AP grains (50 micron each) (model II), and twenty two equal sizes grey AP grains (185 micron each) distributed with smaller sizes of AP grains ( 47 micron each) (model III). The upper portion represents the gas phase and the lower one refers to the solid phase. The circles region in the latter represent the AP grains (gray), while the powder around the circles represent the fuel-binder HTPB. The combustion surface shape through the solid phase show that, the surface is initially flat and then as the solution is advanced, the combustion surface retreats in an unsteady fashion and the morphology of the combustion surface reflects the AP size and distributions. Moreover the differences in shapes of the reaction rates contours $R=R_{1} Q_{g 1}+R_{2} Q_{g 2}$ at $t=1,2,3$, and 4.5 with time illustrate the behaviour of the burning rate at the propellant surface and are used to reconstruct the corresponding flame structures in figures ( $4 a$ and $b)$ and identify the parts of the flame structure that dominate the 2D disk pack burning rate and the surface heat flux. It is noted that, when a significant portion of the surface consists a large AP grains as in the model (I), the local regression is slower than that where mixing of small AP grains with binder occurs as in model (I) and (II) at later times.

In additions these figures (4a) and (4b) show two kind of flames. The first ones are the AP decomposition flames. These flames represents the horizontal flame structures over the combustion surface and lies adjacent to the small and large AP grains. As time advanced, these horizontal shapes converted to curved ones to reflect the burned portions of the AP grains. The second flames are the diffusion flames that generated at the interface between the AP grains and the fuel-binder HTPB. These flames represent the vertical flame structure at the interfaces points between the fuel and oxidizer. As time advanced, these diffusion flames take a different shapes in the gas phase and may meet each other in a very nice way to form another flames away from the combustion surface. Note that the base of some diffusion flames found to be away from the interface between the AP/HTPB region over the large AP grains. This important phenomenon has been noticed also in [21]. The reason behind this shift to the location of the diffusion flames may be related to the stoichiometery and the flux conditions as in figures (5), and (10).

At $t=3$ and 4.5 in figure (4b) for model (I) and model (II), a portion of the combustion surface be very sharp at the end of the burning of the large AP grains. Really these notches show the ability of the current numerical modeling and the level set strategy to deal with this sensitive changes. Moreover, if anyone look carefully to the combustion surface will find a portion of the surface has no flame, or in another word the flame structure over the surface is not continuous. This can occur if the packing process form a fuel-rich regions. Really, this phenomenon is not desired in the rocket propellant burning since it may lead to extinction and in turn rocket failure. 


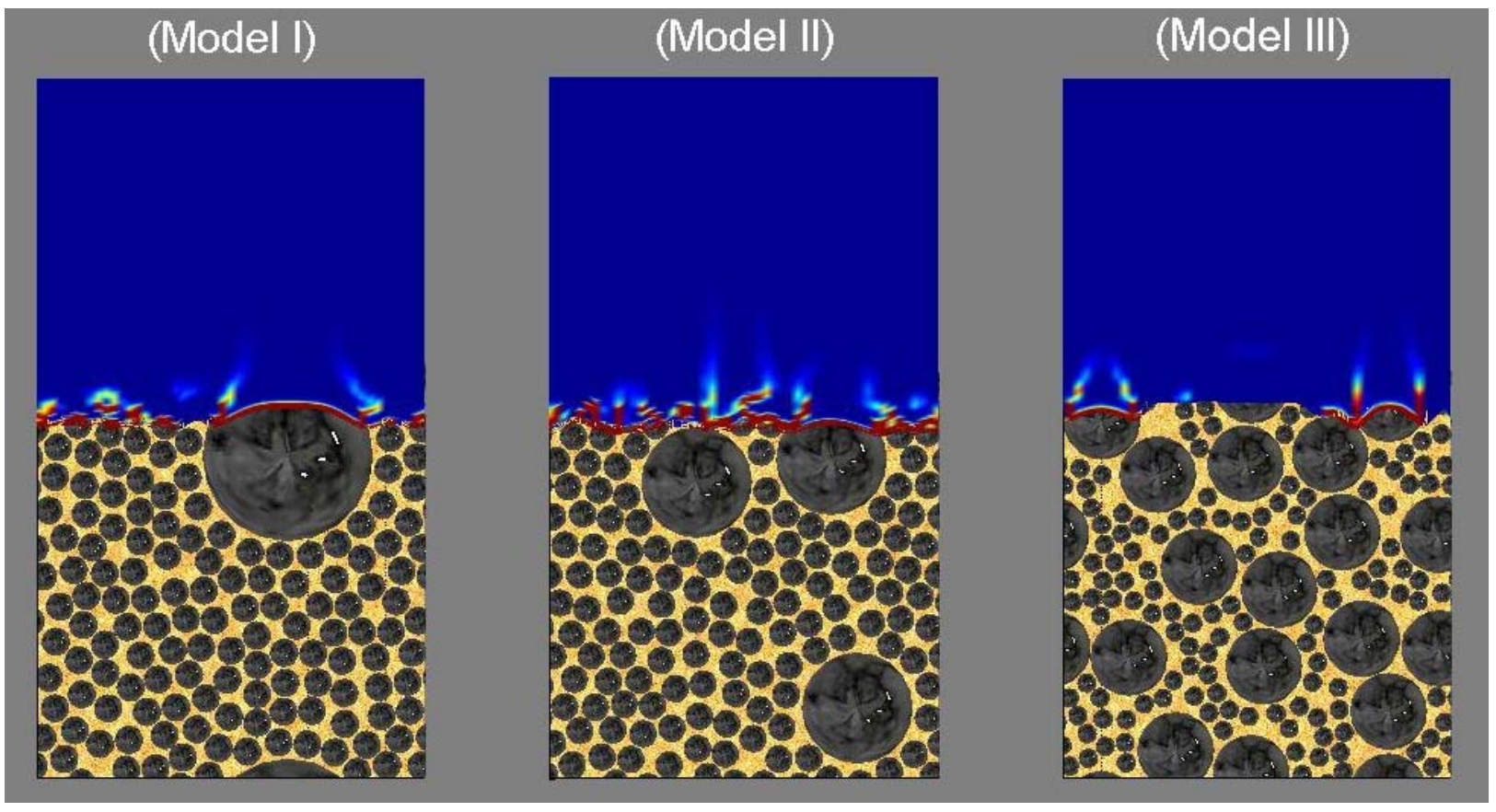

$t=1.0$

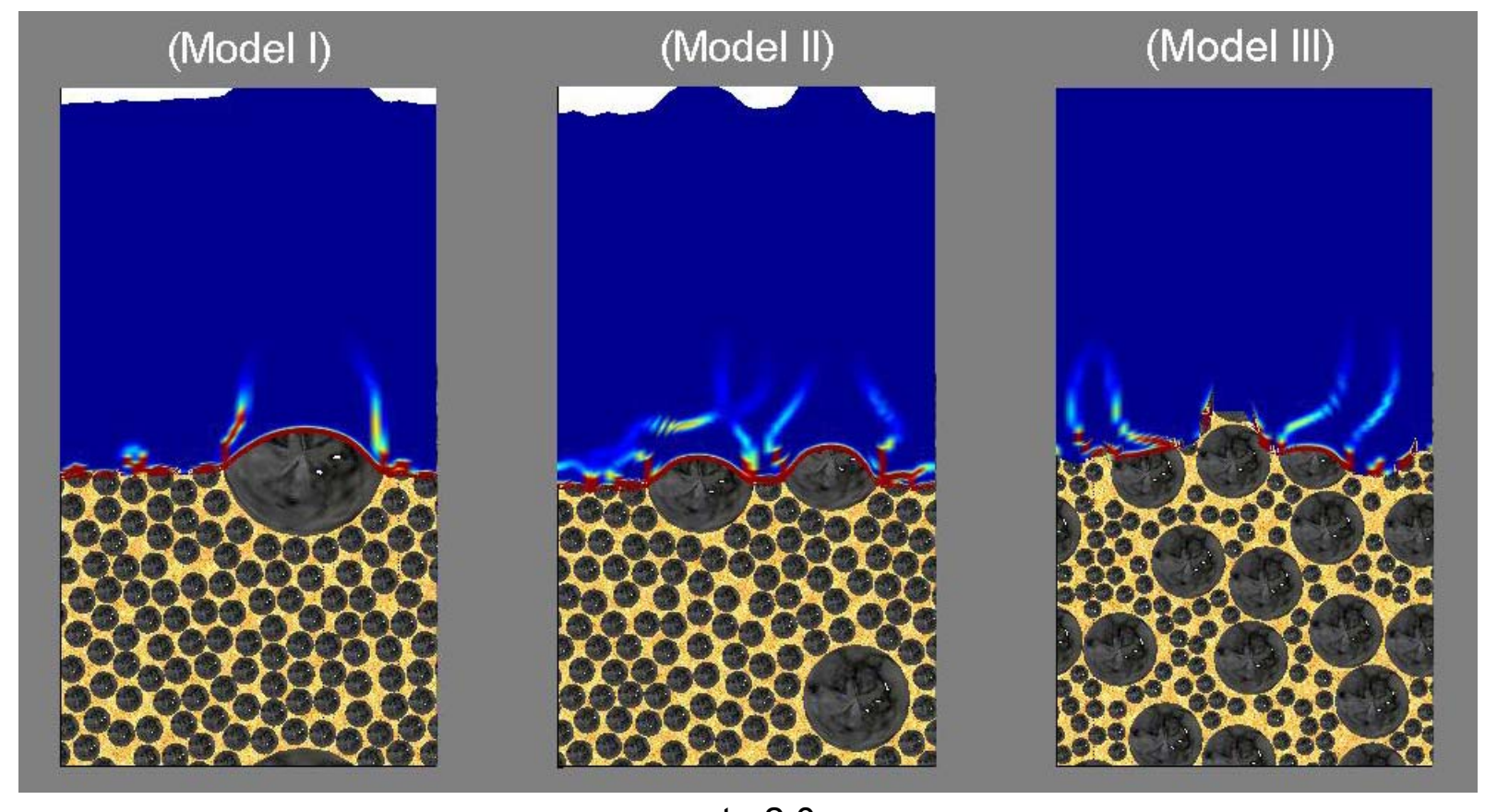

$$
t=2.0
$$

Figure(4a): Reaction rate contours $R=R_{1} Q_{g 1}+R_{2} Q_{g 2}$ at two times a) $t=1.0$ and 2.0 for the three models. 

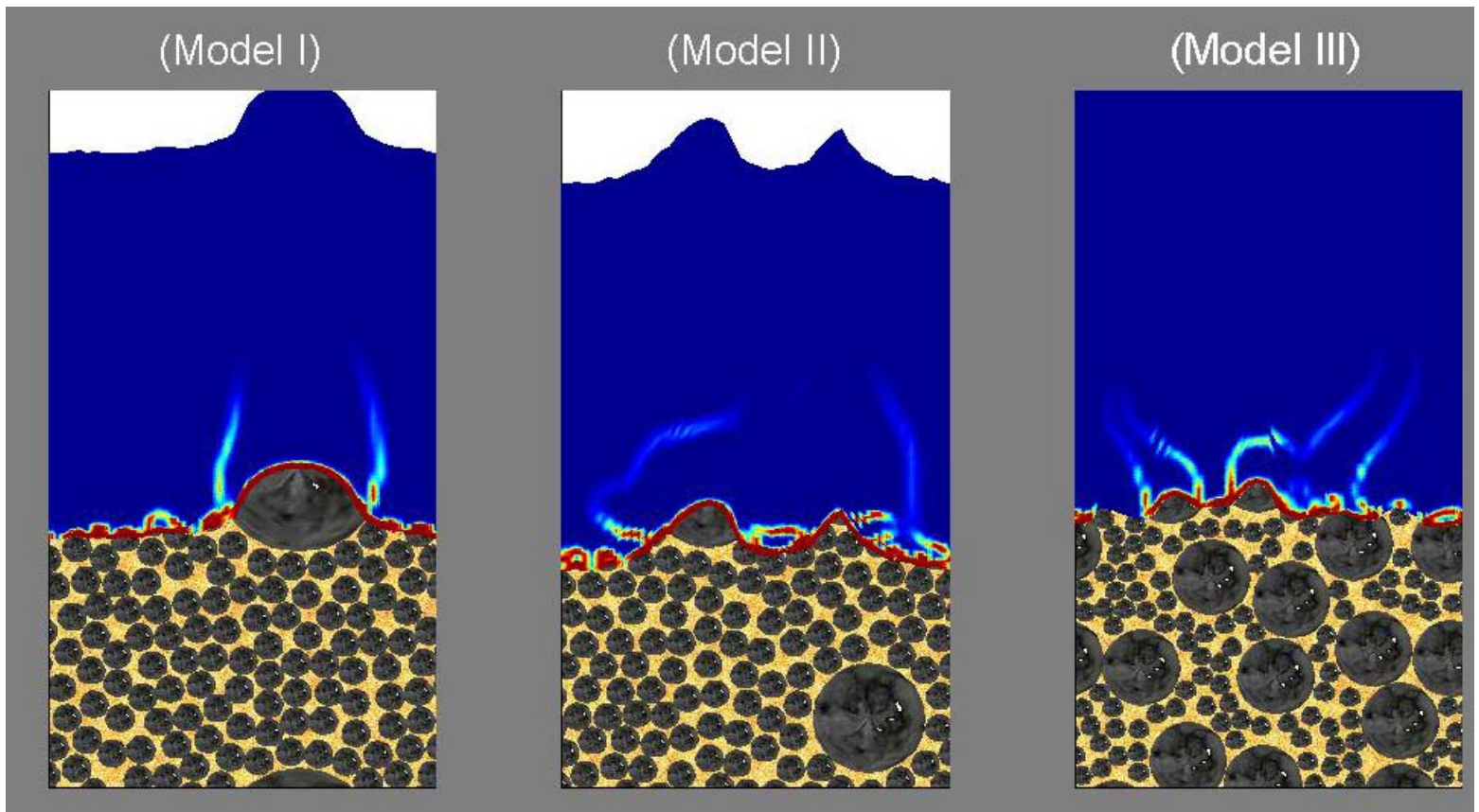

$$
t=3.0
$$

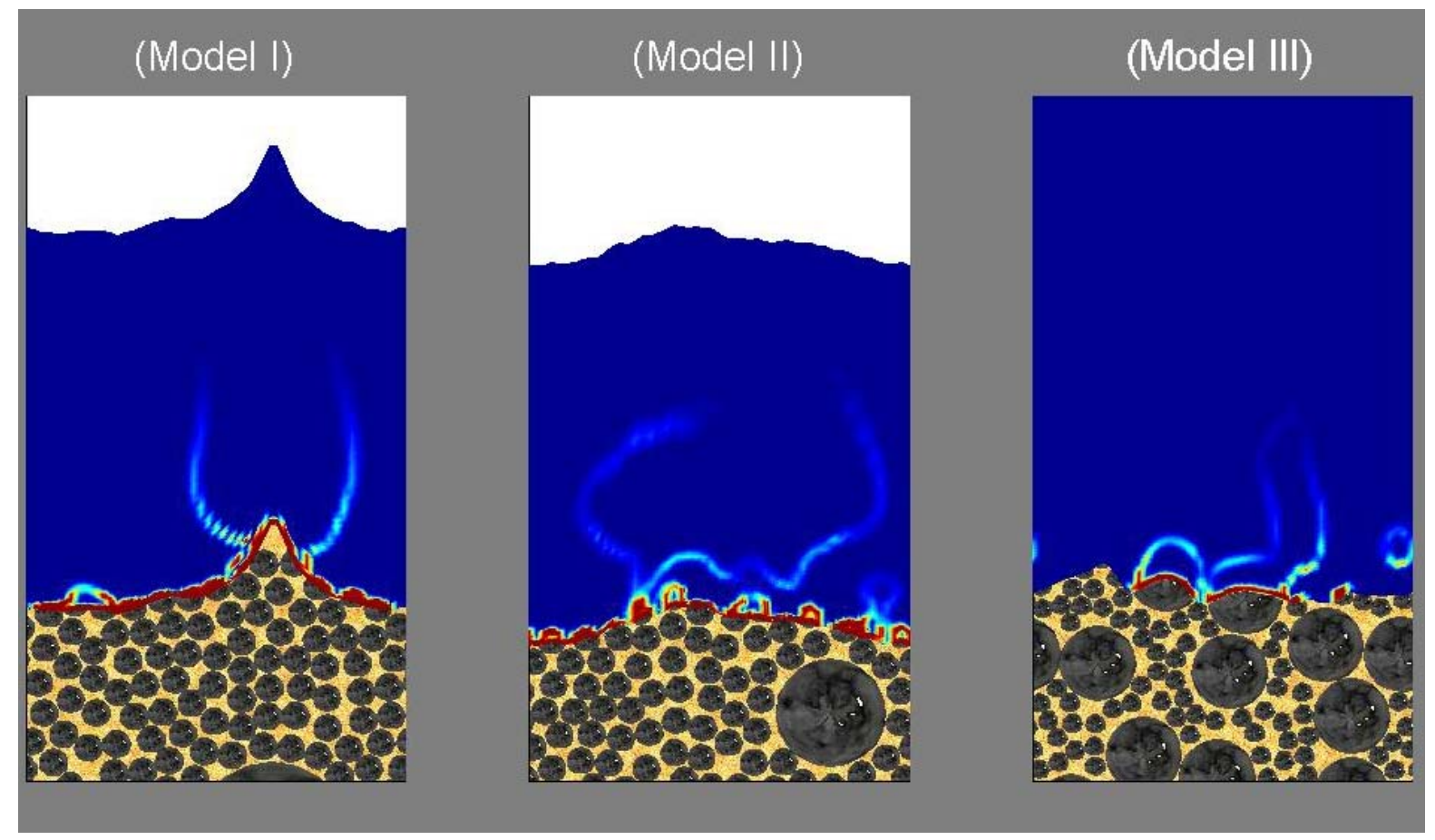

$$
\mathrm{t}=4.5
$$

Figure(4b): Reaction rate contours $R=R_{1} Q_{g 1}+R_{2} Q_{g 2}$ at two times at $t=3.0$ and 4.5 for the three models. 
It is clearly seen that the large AP particles act as a resistance in the way of the combustion process and, in turn, slow the burning of the combustion surface than that with the mixture of small particles imbedded in HTPB powder.

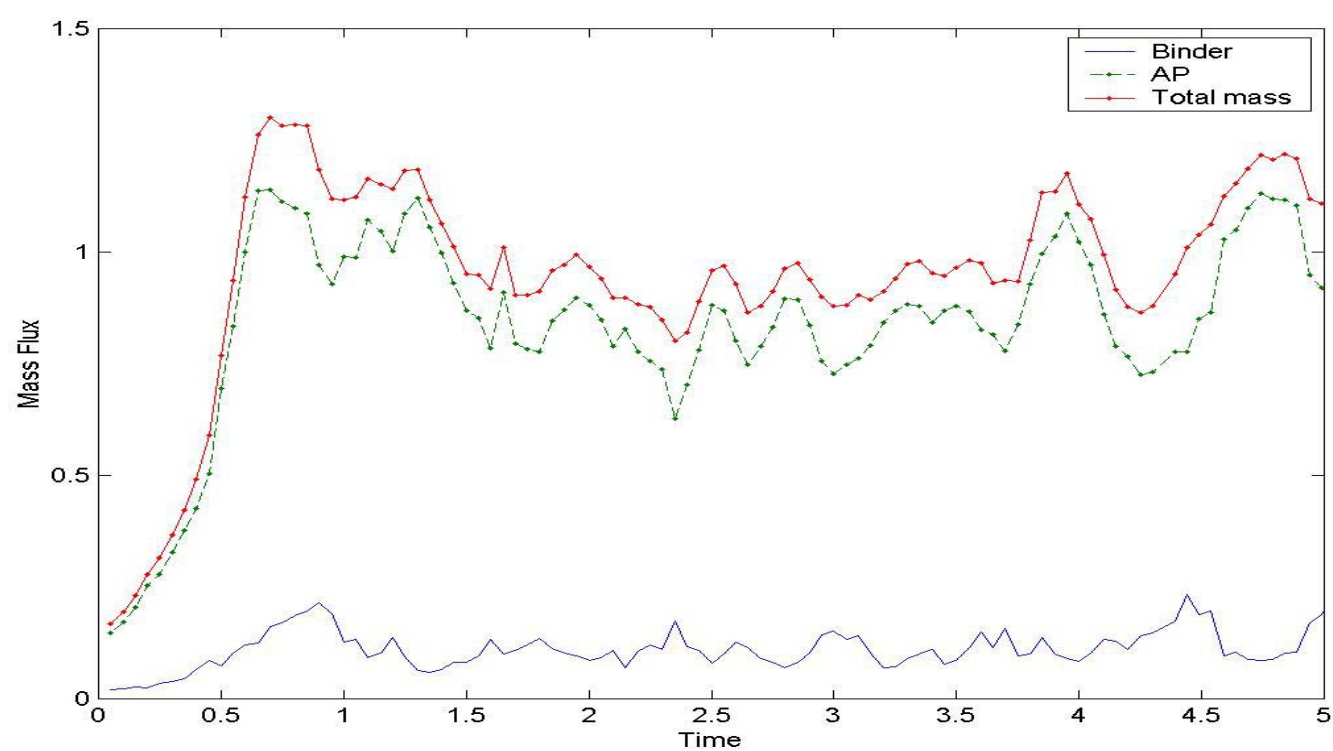

Figure (5): Fluctuations in the surface mass flux from the fuel-binder(HTPB) and the oxidizer (AP) with time for bimodal disk pack in model (I).

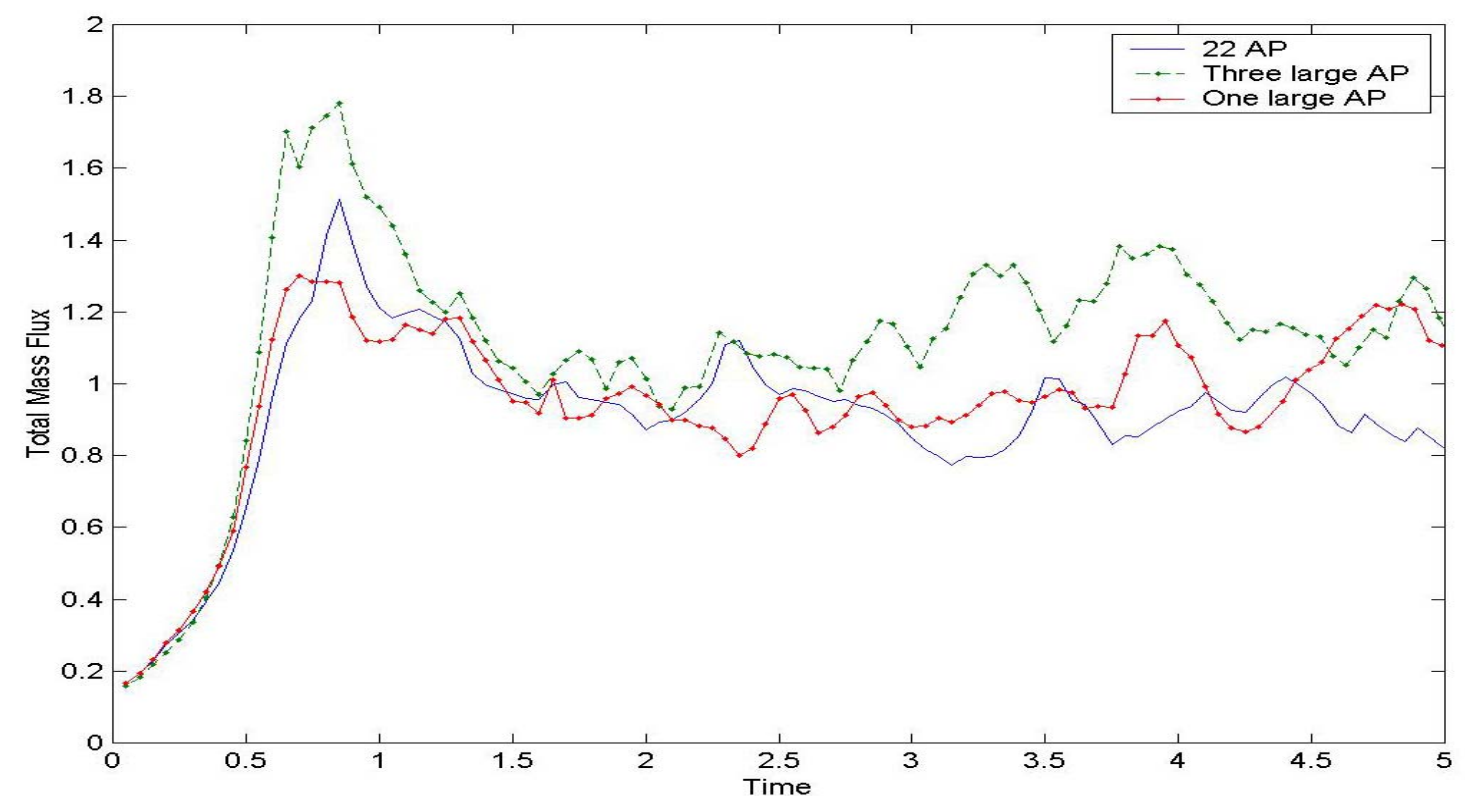

Figure (6): Fluctuations in the surface total mass flux with time for the model (I) one large AP, model (II) three large AP, and model (III) 22 AP. 
Fluctuations in the surface mass flux for the fuel-binder and the AP and their summation are presented in Figure (5). The mass flux is the instantaneous surface integral of the flux through the surface. This result shows that for the time period between $t=0$ to $t=5$ most of the mass flux from the combustion surface arises from the large AP grain (300 micron) since it occupy a significant portion of the combustion surface. The average value of the total mass flux found to be around one.

Figure (6) shows the fluctuations in the surface total mass flux with time for the model (I) one large AP, model (II) three large AP, and model (III) 22 AP. This result shows that the AP sizes and distribution with the fuel binder has a great effect on the average of the total mass flux. It is noted that the average value of the total mass flux generated defined by the random packing of the discs model (II) is greater than that from the random packing of the discs model (I) and (III) figure (3).

Fluctuations of the maximum values of the reaction rate, the gas and solid surface temperatures with times are presented in figures (7), (8), and (9). Figure (7) shows that the maximum values of the reaction rates for the models (II) \& (III) are greater than that for the model (I). As a result, the maximum values of the corresponding gas temperature behave the same trend as in figure (8). For the model (III) the temperature is the gas phase start to oscillate away from the adiabatic flame temperature $\left(T^{\prime}=2700 \mathrm{~K}\right)$ at $t=1.7$, and for the second model at $t=0.75$, while for the first model gas phase temperature don't oscillate with the time period $(t<5)$ since the AP occupy most of the combustion surface. In contrast, these is a slight change with the maximum values of the solid phase surface temperature as figure (9).
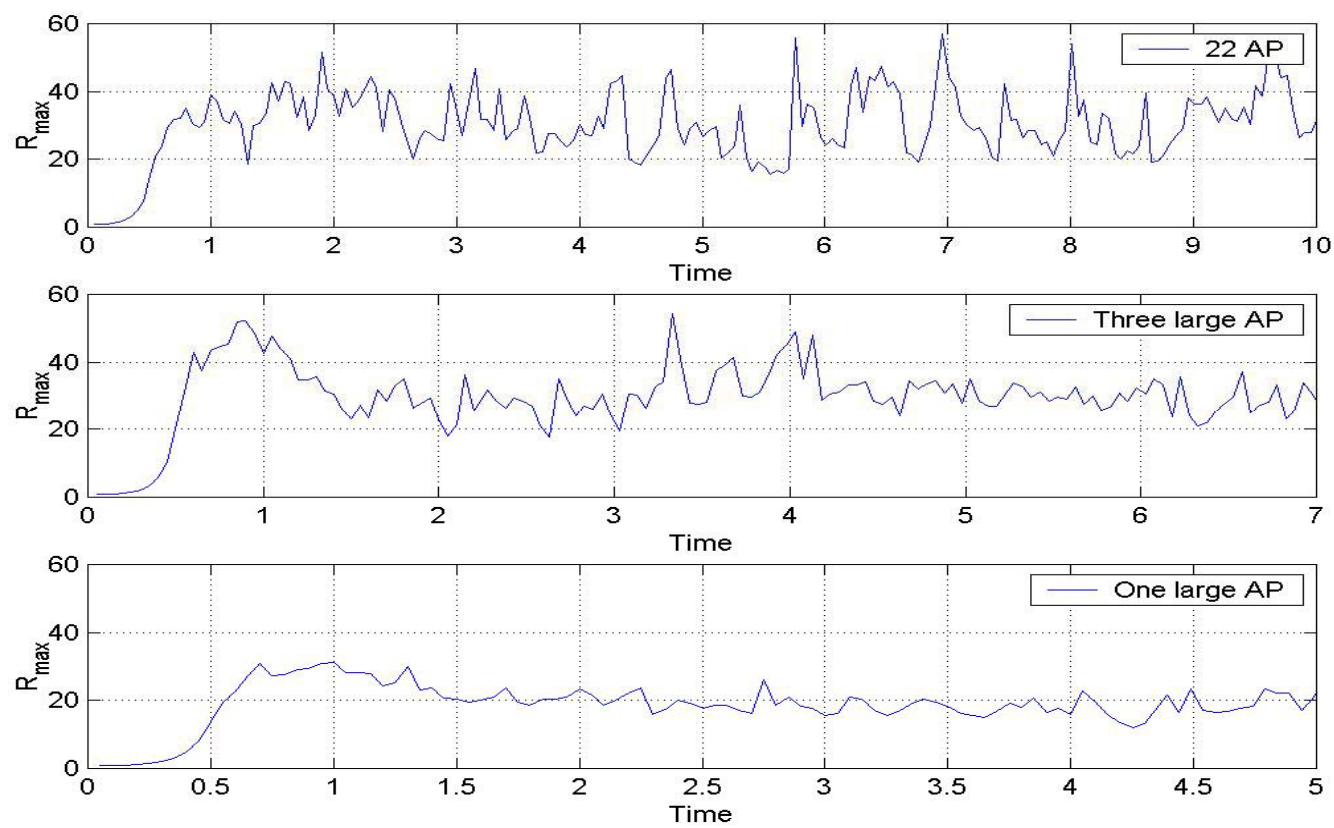

Figure (7): Fluctuations in the maximum values of the reaction rates with time for the model (I) one large AP, model (II) three large AP, and model (III) 22 AP. 

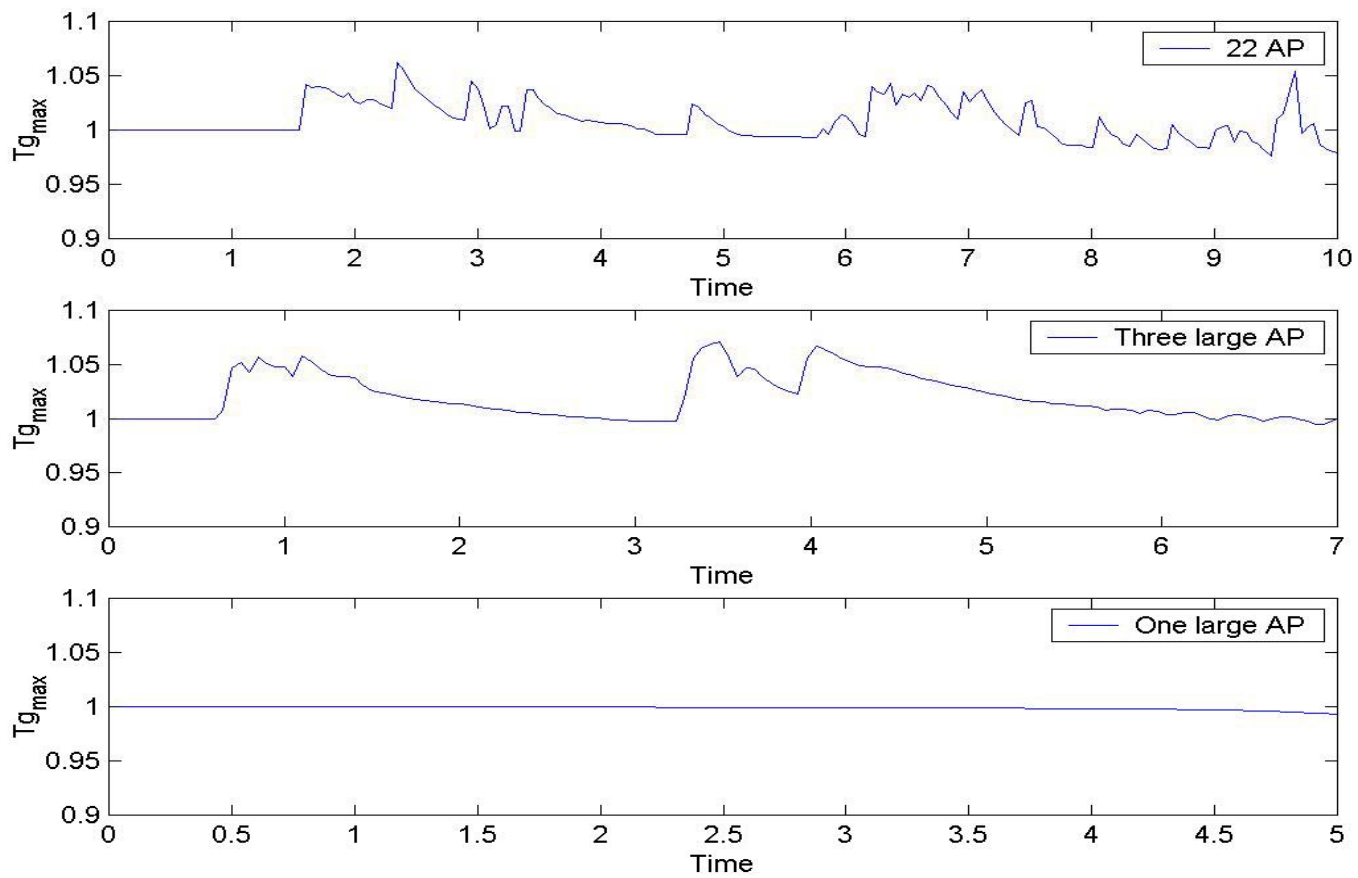

Figure (8): Fluctuations in the maximum values of the gas phase temperature with time for the model (I) one large AP, model (II) three large AP, and model (III) 22 AP.
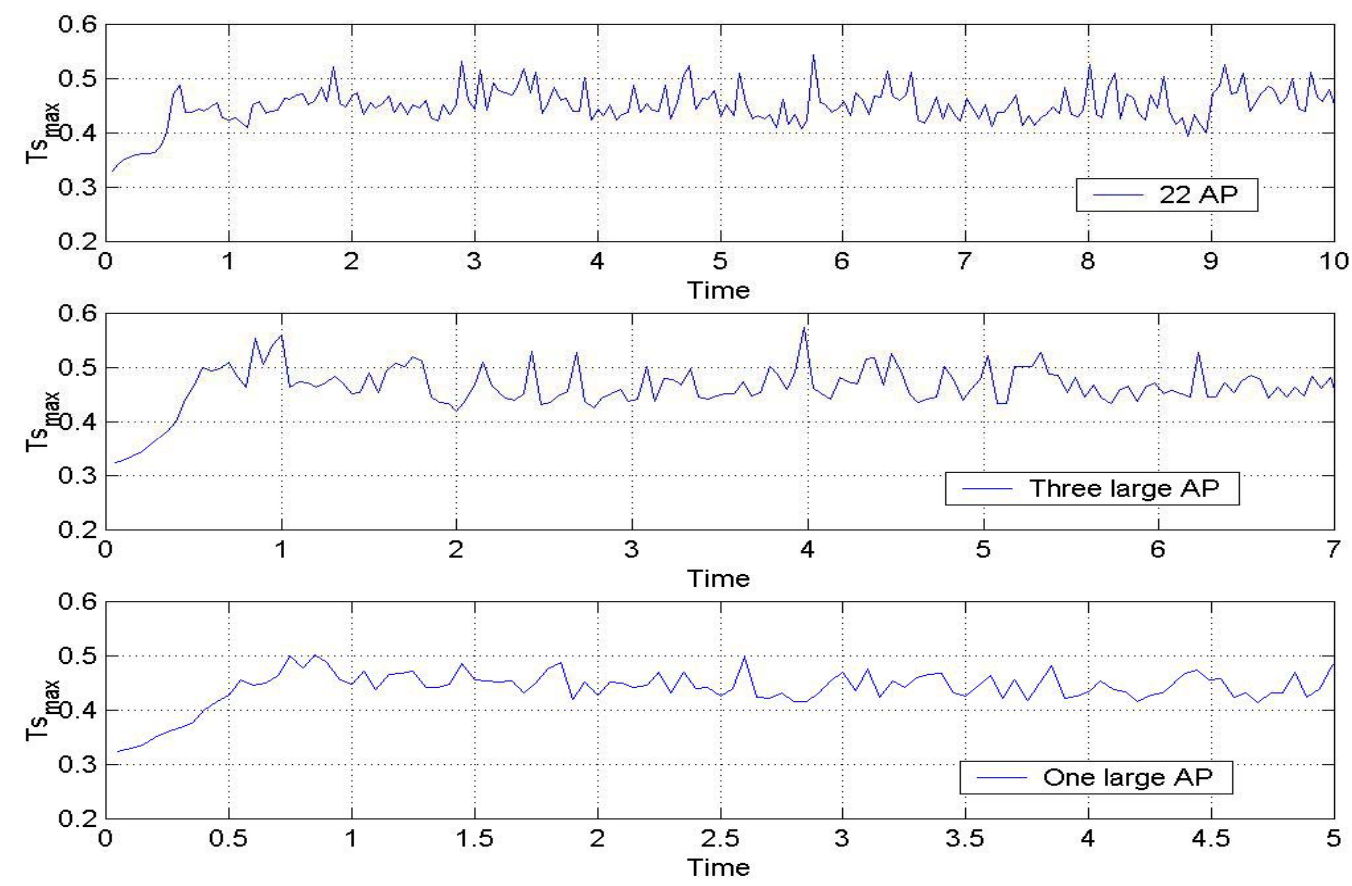

Figure (9): Fluctuations in the maximum values of the solid phase temperature with time for the model (I) one large AP, model (II) three large AP, and model (III) 22 AP. 
Finally the most important fluctuations are for the equivalent ratio which defined as the ratio of the instantaneous mass flux of the binder to that of the AP normalized to the stoichiometric ratios of these two fluxes. The burning process of the combustion surfaces over the burning time period show significantly several intervals for which it is fuel-lean and others for where it is fuel-rich. The equivalent ratios of the defined random packing models (I), (II), and (III) oscillate around the stoichiometery values and strongly fuel-rich and fuel-lean is seen for the model (II) and (III). This result reveal that the random packing process of the three models are packed in the right way and the flame structure over the combustion surface at any time are exist.
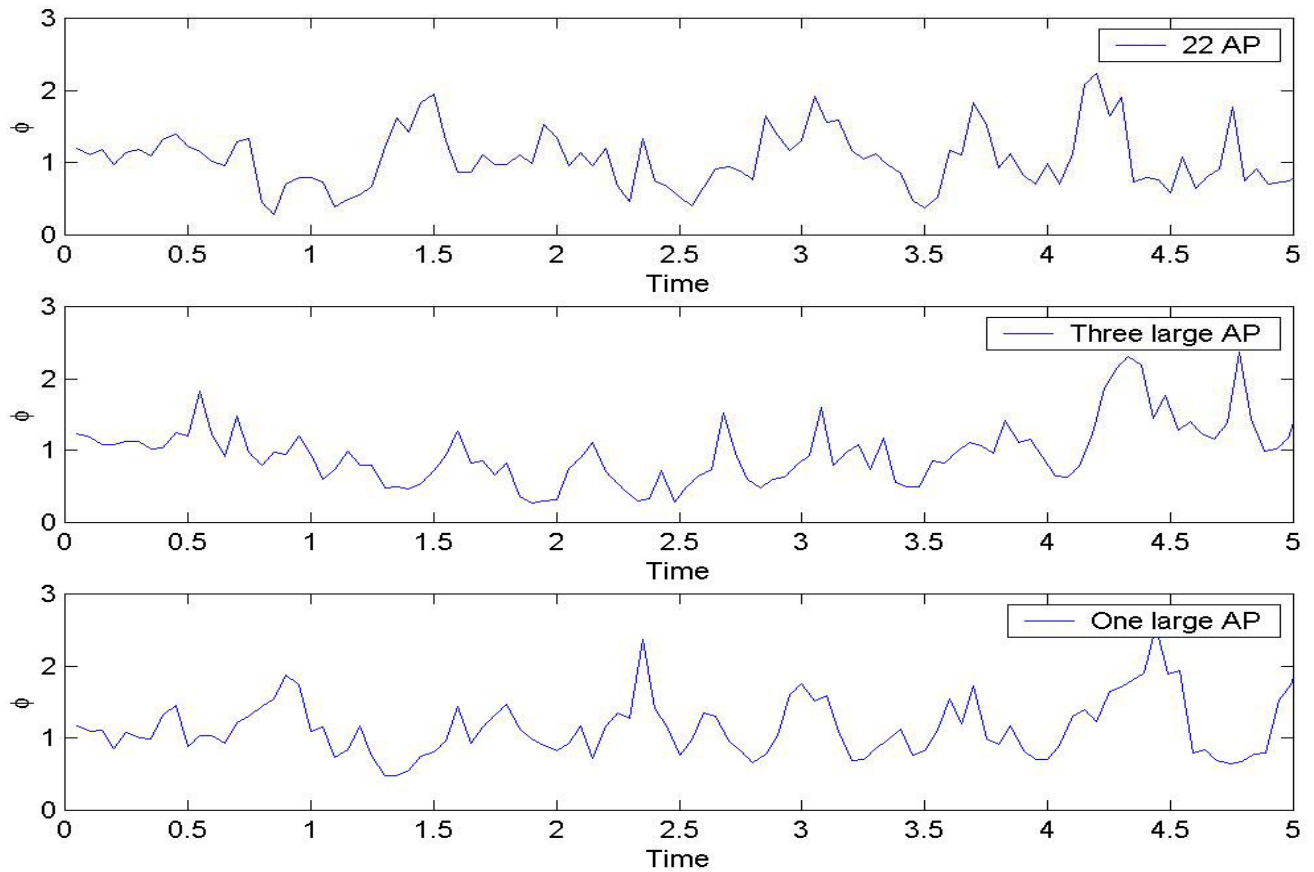

Figure (10): Fluctuations in the equivalent ratio $(\Phi)$ with time for the model $(I)$ one large AP, model (II) three large AP, and model (III) 22 AP.

In general, these oscillations give a good insight about transient behaviuor of the burning process, but didn't reflect the acoustic instability on the large scale models that arises from the coupling effect between the burning process and the transient pressure. Here in this study, we have several figures show the axial variations of the surface gas and solid temperature, burning rate, equivalent ratio and so on. These figures show tenth number of wave cycles over 1000 micron of propellant. Now the question is how many wave cycles suppose to be on the large scale model (say 40 meter long of the propellant). Based on this study we can say $\mathrm{O}\left(10^{6}\right)$ wave cycles expected to be exist with the large scale. There are several studies have been conducted to investigate the acoustic instability on the large scale model by simulating the unsteady burning rate by a 
time-dependent mass injection of inert gas from a transpired side-wall. The recent one by Hegab and Kassoy, 2006,[32]used wave number for the surface morphology $n=1,3$, and 5. what happens to the cold model simulation if $n \sim O\left(10^{6}\right)$. We think that the results of the small scale models as the current study can strongly affect the nature of the flow field for large scale one.

\section{CONCLUSION}

Few decades ago the details of the heterogeneous propellant combustion has been discussed. The theoretical framework consists of a 2D physical pictures, but most modeling efforts have been adapted 1D mathematical model as in [1,2,3, and 4]. This has obviously been of value and important insights have been achieved, but the multidimensional numerical framework is required.

Here, 2D calculations to the combustion of heterogeneous solid propellant, accounting for the gas phase physics, the solid phase physics and an unsteady non-planar description of the regressing propellant surface is developed. Three different random packing disc models for the AP particles imbedded in a matrix of fuel-binder are used as a base of our combustion code. These models have different AP grain sizes and distribution within the fuel binder.

A number of issues have been discussed such as dependence of the speed by which the combustion surface recedes on the exposed pressure in the gas phase, the effect AP grain sizes and distribution with the fuel-binder HTPB on the shape of the combustion surface and the flame structure. Fluctuations in a number surface-defined quantities are presented for three different random discs packing for bimodal models. It is clearly seen that the AP grain size has a great effect not only on the combustion surface and the generated flame structure but also on the gas/solid phases and interface temperature, the equivalent ratios, and surface mass flux as well.

It is clearly seen that the large AP particles act as a resistance in the way of the combustion process and, in turn, slow down the burning of the combustion surface comparing with the mixture of small particles imbedded in HTPB powder.

In general, the fluctuations here gave a good insight about the transient behaviuor of the burning process, but didn't reflect the acoustic instability on the large scale models that arises from the coupling between the burning process and the transient pressure. As a result, more intensive computational work is still needed to study the effect of crossflow in solid rocket motor chamber on the burning rate of a real long scale multimodal composite propellant.

\section{ACKNOWLEDGMENTS}

Hegab A.M., would like to thank the research team at the Center for Simulation of Advanced Rocket (CSAR), University of Illinois at Urbana-Champaign (UIUC), USA in particularly Prof. J. Buckmaster and Prof. T. Jackson for their encouragement, help and cooperation for building the original versions of these codes. 


\section{REFERENCES}

1. M.W. Beckstead, R.L. Derr, and C.F. Price, "A Model of Composite SolidPropellant Combustion Based on Multiple Flames", AIAA Journal, 8(12):22002207, (1970).

2. B. Rasmussen and Jr. R.A. Frederick, "A Nonlinear Heterogeneous Model of Composite Solid Propellant Combustion", AIAA Paper No. 99-2228, In $35^{\text {th }}$ AIAA/ASME/SAE/ASEE Joint Propulsion Conference, June (1999).

3. J.J. Murphy and H. Krier , "Heterogeneous effects on Dynamic Burning in Composite Solid Propellant" Proceeding of the Combustion Institute, 28, (2000).

4. S. Lee, E. Price, and R. Sigman, "Effect of Multidimensional Flamelets in Composite Propellant Combustion", Journal of Propulsion and Power, Vol.10(6), PP 761-768, (1994).

5. E.Price, J.Handley, R.Panyam, R.Sigman, and A.Ghosh, "Combustion of Ammonium Pechlorate-Polymer Sandwiches", AIAA Journal, Vol.19, No. 3, PP, 380-386, (1981).

6. A. Al-Harthi and A. Williams, "Effect of fuel binder and oxidizer particle diameter on the combustion of ammonium perchlorate based propellants" Fuel, Vol. 77, No. 13, pp1451-1468, (1998).

7. T.L.Jackson, J. Buckmaster, and A. Hegab, "Periodic Propellant Flames and Fluid-Mechanical Effects”, Vol. 17, Number 2, Pages 371-379, (2001).

8. J. Buckmaster, T.L. Jackson, and J. Yao, "An Elementary Diffusion of Propellant Flame Geometery”, Combustion and Flame Vol. 117, PP 541-552, (1999).

9. T.L.Jackson, J. Buckmaster, and J. Hoeflinger, "Three-Dimensional Flames Supported by Heterogeneous Propellants", JANNAF Paper, JANNAF CS/PSHS/APS Joint Meeting, Cocoa Beach, FL. October (1999).

10. T.L. Jackson and J. Buckmaster, "Nonpremixed Periodic Flames Supported by Heterogeneous Propellant", Journal of Propulsion and Power, Vol.16(3), PP 498504, (2000).

11. W. Cai and V. Yang, "A Model of AP/HTPB Composite Propellant Combustion", AIAA Paper 2000-0311, 38 ${ }^{\text {th }}$ Aerospace Science Meeting (2000).

12. R.H. Waesche and J. Wenograd, "Calculation of Solid Propellant Burning Rate from Condensed-Phase Decomposition Kinetics", AIAA Paper 69-145, N. Y., Jan. (1969).

13. C.E. Hermance, "A Model of Composite Propellant Combustion Including Surface Heterogeneity and Heat Generation", AIAA Journal, Vol.4 PP 1629-1637, (1960).

14. A. Hegab, T. Jackson, J. Buckmaster, and S. Stewart, "The Burning of Periodic Sandwich Propellants", $36^{\text {th }}$ AIAA/ASME/SAE/ASEE Joint Propulsion Conference, AIAA Paper 2000-3459, (2000).

15. A. Hegab, T. Jackson, J. Buckmaster, and S. Stewart, "Nonsteady Burning of Periodic Sandwich Propellant with Complete Coupling between the Solid and Gas Phases" Combustion and Flame, Vol. 125(1/2), PP 1055-1070, (2001).

16. G.M. Knott and M.Q. Brewster, "Two-Dimensional Combustion Modeling of Heterogeneous Propellants with finite Peclet Number", Combustion and Flame, Vol. 121(1/2), PP 91-106, (2000). 
17. McGeary, R. K., "Mechanical Packing of Spherical Particles," Journal of the American Ceramic Society, Vol. 44, No. 10, 1961, pp. 513-522.

18. Kochevets, S., Buckmaster, J., and Jackson, T. L., "Random propellant packs and the flames they support", 36th AIAA/ASME/SAE/ASEE Joint Propulsion Conference.AIAA Paper 2000-3461, 2000.

19. Kochevets, S., Buckmaster, J., and Jackson, T., and Hegab, A.,"Random Packs and their Use in Modeling Heterogeneous Solid Propellant Combustion", Journal of Propulsion \& Power Vol.17 No.4, pp. 883-891, July-Aug. 2001.

20. Knott, G. M., Jackson, T. L., and Buckmaster, J., "The Random Packing of Heterogeneous Propellants," AIAA Journal, Vol. 39, No. 4, pp. 678-686.

21. Buckmaster, J., Jackson, T. L., Hegab, A., and Kochevets, S., "Modeling Propellants and Modeling Propellant Flames," 37th JANNAF Combustion Meeting, 2000.

22. Buckmaster J., Jackson T., Hegab A., Kochevets S., Ulrich M. "Randomly Packed Heterogeneous Propellants and the Flame They Support" AIAA paper 2001-0337, 39th. Aerospace Science Meeting, Reno, NV, 2001.

23. Lubachevsky, B. D., and Stillinger, F. H., "Geometric Properties of Random Disk Packings," Journal of Statistical Physics, Vol. 60, Nos. 5/6,pp. 561-583, 1990.

24. Lubachevsky, B. D., Stillinger, F. H., and Pinson, E. N., "Disks vs. Spheres: Contrasting Properties of Random Packings," Journal of Statistical Physics, Vol. 64, Nos. 3/4, pp. 501-524, 1991.

25. Hegab, A.M. " Random Packing of Bimodal and Multimodal Heterogeneous Propellant", in press, 2007.

26. Hegab, A.M. (2003), "Modeling of Microscale Solid Propellant Combustion"; The Tenth International Conference on Aerospace Science \& Aviation Technology, ASAT-10, May 13-15, 2003, Cairo, Egypt.

27. Hegab, A.M. (2003), "Combustion Modeling of Micro-Structure Solid Propellant ";Engineering Research Journal ERJ, Minufiya University, Vol. 26, No.3, July 2003.

28. A. Harten, "Uniformly High Order Accurate Essentially Non-oscillatory Schemes, III", Journal of Computational Physics, 71, 231-303, (1987).

29. G. Jiang and C. Shu "Efficient Implementation of Weighted ENO Scheme", Journal of Computational Physics, 126, 202-228, (1996).

30. Handley, J.C. and Strahle, W.C. "The Behaviour of Several Catalysts in the Combustion of Solid Propellant Sandwiches", AIAA Paper 74-122, Washington, D.C., (1974)

31. M.Q. Brewster, G.M. Knott, B.T. Chorpening, "Combustion of AP/HTPB Laminate Propellants", AIAA Paper 2001-4501, $37^{\text {th }}$ AIAA/ASME/SAE/ASEE Joint Propulsion Conference, Salt Lake City, UT, USA, (2001).

32. Hegab, A.M. and Kassoy, D.R. Internal Flow Temperature and Vorticity Dynamics in Channel with Transient Mass Addition, AIAA Journal, Vol. 44, 4, 2006. 